\title{
Genetic Optimization based Adaptive Fuzzy Logic Control of a pH Neutralization Process
}

\author{
Parikshit Kishor Singh $^{1}$, Surekha Bhanot ${ }^{2}$ and Hare Krishna Mohanta ${ }^{3}$ \\ ${ }^{1}$ Dept. of Electronics \& Instrumentation, BITS Pilani, India \\ ${ }^{2}$ Dept. of Electronics \& Instrumentation, BITS Pilani, India \\ ${ }^{3}$ Dept. of Chemical Engineering, BITS Pilani, India \\ ${ }^{1}$ parikshit_singh@pilani.bits-pilani.ac.in, ${ }^{2}$ surekha@pilani.bits-pilani.ac.in, \\ ${ }^{3}$ harekrishna@pilani.bits-pilani.ac.in
}

\begin{abstract}
Presence of severe nonlinearity in $\mathrm{pH}$ neutralization process makes the problem of $\mathrm{pH}$ control a difficult and challenging one. Further, optimized control of such highly nonlinear system requires tuning of various parameters with a suitable evolutionary algorithm (EA). This paper presents genetic algorithm (GA) based unconstrained, continuous and single-objective optimization of conventional and adaptive nonlinear fuzzy logic control (FLC) of $\mathrm{pH}$ neutralization process for servo and regulatory operations. The GA optimized adaptive FLC scheme changes the universe of discourse of input-output membership functions based on the region of operation and amount of step change in set-point and load. The performance of controllers are evaluated using integral of squared errors (ISE) and tested for random step changes in set-point and load.
\end{abstract}

Keywords: Fuzzy control; genetic algorithm; pH neutralization; nonlinear; adaptive; optimization

\section{Introduction}

Highly nonlinear behavior and time varying parameters of $\mathrm{pH}$ process makes it a benchmark for modeling and control of nonlinear processes. $\mathrm{pH}$ control plays an important role in many industrial process applications such as wastewater treatment in paper and pulp plants, boiler feedwater treatment in thermal power plants, biopharmaceutical plants, food processing plants, and various other chemical processing plants. In recent years the increased complexity of the processes, stringent requirements of product quality and conformance with strict environmental and safety regulations has led to research efforts in design and development of "intelligent" $\mathrm{pH}$ control systems. Intelligent control can be described as a control approach that tries to imitate important characteristics of the human brain and human way of thinking and decision making. It is also a term that is commonly used to describe control schemes that are based on artificial intelligence (AI) techniques such as neural networks, fuzzy logic, genetic algorithm (GA), and their hybrid combinations.

Early works on $\mathrm{pH}$ control involved development of first-principle based dynamic $\mathrm{pH}$ process model and their use in feedback, feedforward and adaptive control techniques [1, 2], [3]. One of the approaches proposed use of material balances and electroneutrality relations on component ions for dynamic $\mathrm{pH}$ process model and time-optimal $\mathrm{pH}$ control $[4,5]$. Because of its simplicity, this model has been used by many researchers as a platform to introduce AI based control techniques [6-8]. In addition, dynamic $\mathrm{pH}$ models based on reaction invariant and strong acid equivalent were designed for various nonlinear and adaptive control schemes [9-13].

Fuzzy logic is based on fuzzy set theory [14]. A fuzzy set deals with an ambiguous and imprecise class of objects which are characterized by membership functions with degrees 
assigned between 0 and 1. Fuzzy logic introduced concept of linguistic variables, fuzzy conditional statements and fuzzy inference system (FIS) to analyze an ill-defined complex systems and decision processes [15]. Though fuzzy logic brought an unconventional shift in nature of computing based on words and perceptions it faced however initial resistances from eminent but incredulous scientists and researchers [16]. Almost a decade later the synthesis of fuzzy logic control (FLC) schemes, famously known as Mamdani type FLC, for a small boiler steam engine combination could be realized [17, 18]. Selforganizing fuzzy controller having capability to modify its control rule base were also developed $[19,20]$. Further an alternative and simpler Sugeno type FLC scheme were also applied for system identification and control [21]. Fuzzy logic has been extensively applied to obtain intelligent equivalent of the conventional counterpart such as proportional-integral (PI), proportional-integral-derivative (PID), sliding-mode and model predictive control techniques [22-25].

Evolutionary algorithms (EAs) are population based search techniques in which optimal solution is reached by a candidate on the basis of Darwin's theory of biological evolution. As per Darwinian theory, the principle of natural selection favors those species for survival and further evolution which are fittest. Over a number of years, various but independent types of EAs such as evolution strategies, evolutionary programming, GA, and genetic programming were invented and developed by many scientists and researchers with an aim of utilizing them for optimal solution of various engineering problems [26, 27]. However, GA conceived by Holland and its variants developed by his associated team members received wide attention [28], [29]. GAs contributed immensely to many scientific and engineering applications [30]. GA is also applied for parameters optimization of various controllers [31-35].

\section{Dynamic Modeling of pH Neutralization Process}

The $\mathrm{pH}$ neutralization process is assumed to take place in continuous stirred tank reactor (CSTR) with perfect mixing and a constant volume. The CSTR has two influent streams: the hydrochloric acid as titration stream (feed A) and the sodium hydroxide as process stream (feed B), and one effluent stream. Based on principle of material balances, the mass balance equation can be written as:

$$
\begin{aligned}
& V\left(d x_{a} / d t\right)=F_{a} C_{a}-\left(F_{a}+F_{b}\right) x_{a} \\
& V\left(d x_{b} / d t\right)=F_{b} C_{b}-\left(F_{a}+F_{b}\right) x_{b}
\end{aligned}
$$

The definitions and numerical values of the variables and parameters used for simulating Eq. (1) and (2) are: $\mathrm{V}$ is the constant volume of the CSTR (1.9 L); $\mathrm{C}_{\mathrm{a}}$ is the concentration $(0.05 \mathrm{~mol} / \mathrm{L})$ and $\mathrm{F}_{\mathrm{a}}$ is the flow rate $(0$ to $6.23 \mathrm{~mL} / \mathrm{s}$ i.e., 0 to $100 \%)$ of acidic stream $A ; C_{b}$ is the concentration $(0.05 \mathrm{~mol} / \mathrm{L})$ and $\mathrm{F}_{\mathrm{b}}$ is the flow rate $(0$ to 6.23 $\mathrm{mL} / \mathrm{s}$ i.e., 0 to $100 \%)$ of basic stream $\mathrm{B} ;\left(\mathrm{F}_{\mathrm{a}}+\mathrm{F}_{\mathrm{b}}\right)$ is the flow rate of the effluent stream; $\mathrm{x}_{\mathrm{a}}$ is the concentration of acid component (chloride ion, $\mathrm{Cl}^{-}$) in the effluent stream (in $\mathrm{mol} / \mathrm{L}$ ); $\mathrm{x}_{\mathrm{b}}$ is the concentration of base component (sodium ion, $\mathrm{Na}^{+}$) in the effluent stream (in $\mathrm{mol} / \mathrm{L}$ ).

The equilibrium relationship for water is given as

$$
\mathrm{K}_{\mathrm{w}}=\left[\mathrm{H}^{+}\right]\left[\mathrm{OH}^{-}\right]
$$

where $\mathrm{K}_{\mathrm{w}}$ is the dissociation constant of water $\left(10^{-14}\right)$.

From the electroneutrality condition, we have

From the electroneutrality condition, we have

$$
\left[\mathrm{Na}^{+}\right]+\left[\mathrm{H}^{+}\right]=\left[\mathrm{Cl}^{-}\right]+\left[\mathrm{OH}^{-}\right]
$$


All of the $\mathrm{Cl}^{-}$ion comes from the $\mathrm{HCl}$ and all of the $\mathrm{Na}^{+}$ion comes from the $\mathrm{NaOH}$. Using Eq. (3) and (4), we have

$$
\left[H^{+}\right]^{2}-\left(x_{a}-x_{b}\right)\left[H^{+}\right]-K_{w}=0
$$

From the definition of $\mathrm{pH}=-\log _{10}\left[\mathrm{H}^{+}\right]$, the $\mathrm{pH}$ titration curve for a strong acidstrong base is given by

$$
\begin{aligned}
& p H=-\log _{10}\left(\frac{x}{2}+\sqrt{\frac{x^{2}}{4}+K_{w}}\right) \\
& \text { where } \mathrm{x}=\left(\mathrm{x}_{\mathrm{a}}-\mathrm{x}_{\mathrm{b}}\right)
\end{aligned}
$$

\section{Design of FLC}

The fuzzy controller for $\mathrm{pH}$ neutralization process is based on Sugeno FIS. The FIS consists of an input fuzzification stage, a fuzzy rule processing stage, and an output defuzzification stage. The fuzzifier stage determines the degree (varying between 0 and 1 ) of belonging of input to different membership functions. Since the antecedent of rule has more than one part, the AND fuzzy algebraic product operator has been applied to obtain the firing strength for that rule. The output level of each rule is weighted by the above firing strength. The final defuzzified output of the FIS is the weighted average of all rules' outputs.

The input variables used for the Sugeno FIS are error $\mathrm{e}(\mathrm{k})=\mathrm{pH}_{\mathrm{SP}}-\mathrm{pH}(\mathrm{k})$ i.e., the difference between the desired setpoint for $\mathrm{pH}$ as $\mathrm{pH}_{\mathrm{SP}}$ and measured values of $\mathrm{pH}$ at the $\mathrm{k}^{\text {th }}$ sampling instant as $\mathrm{pH}(\mathrm{k})$, and change in error ce $(\mathrm{k})=\mathrm{e}(\mathrm{k})-\mathrm{e}(\mathrm{k}-1)$ i.e., the difference between the error at the $\mathrm{k}^{\text {th }}$ and $(\mathrm{k}-1)^{\text {th }}$ sampling instants. The output variable for Sugeno FIS is controller output co(k). The change in manipulated variable is the change in acid flow rate i.e. $\operatorname{col}(\mathrm{k})=\mathrm{F}_{\mathrm{a}}(\mathrm{k})-\mathrm{F}_{\mathrm{a}}(\mathrm{k}-1)$. The input variables are expressed in $\mathrm{pH}$ and output variable is expressed in \%. The membership functions for the input variables (e, ce), and output variable (co) are shown in Figures 1, 2, and 3 respectively.

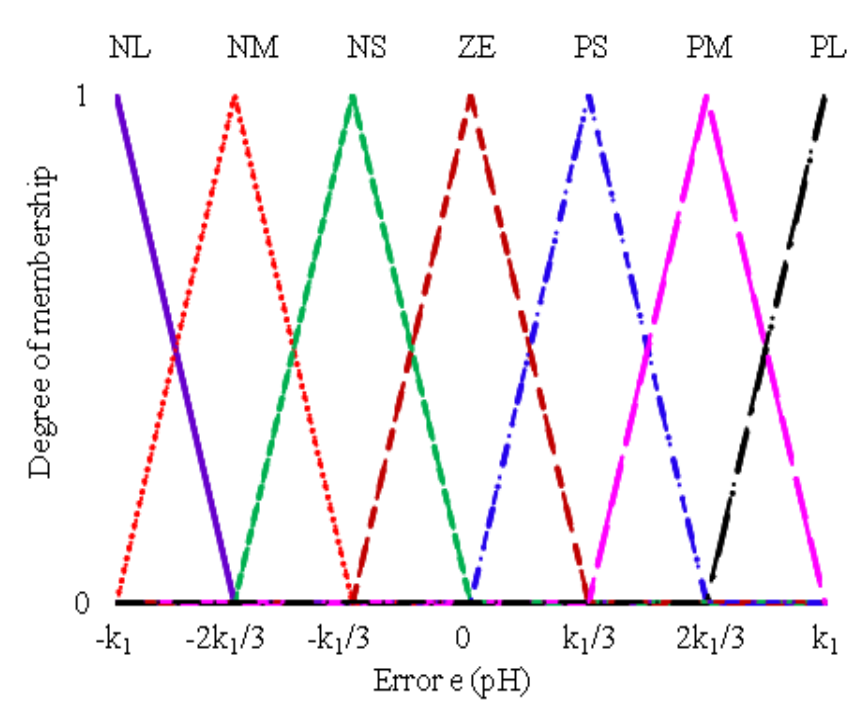

Figure 1. Membership Functions for Error 


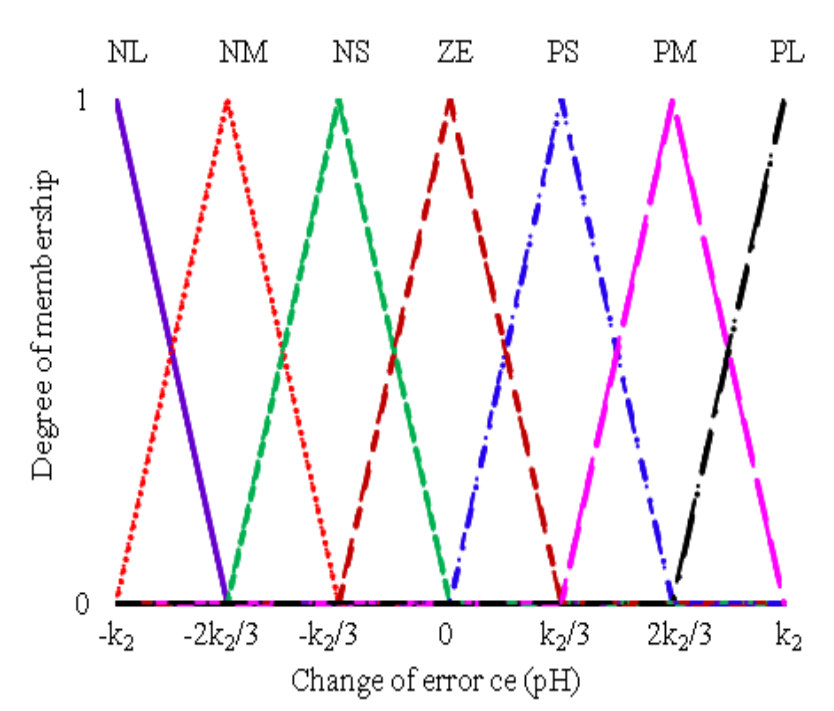

Figure 2. Membership Functions for Change of Error

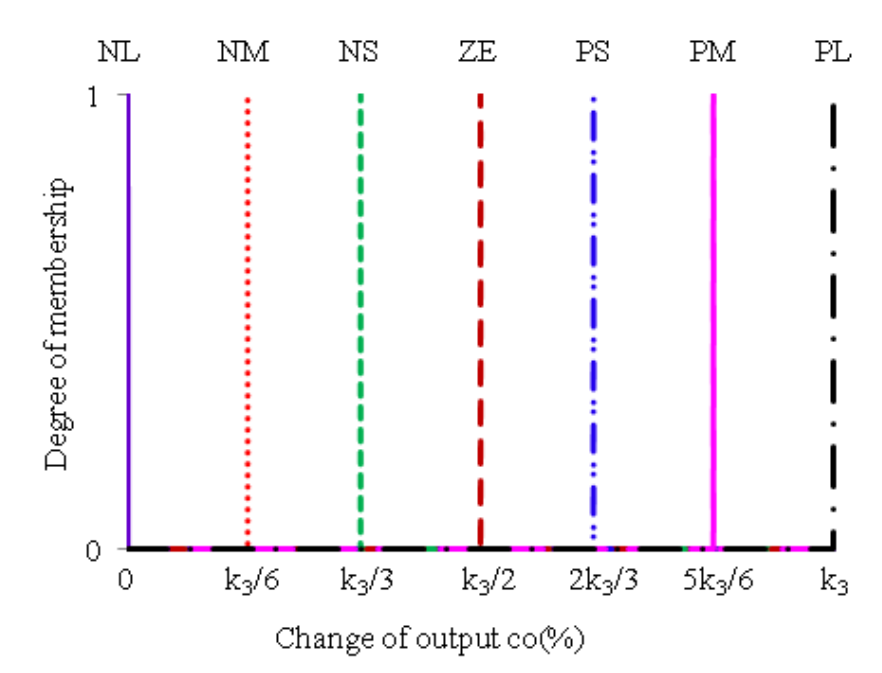

Figure 3. Membership Functions for Change of Output

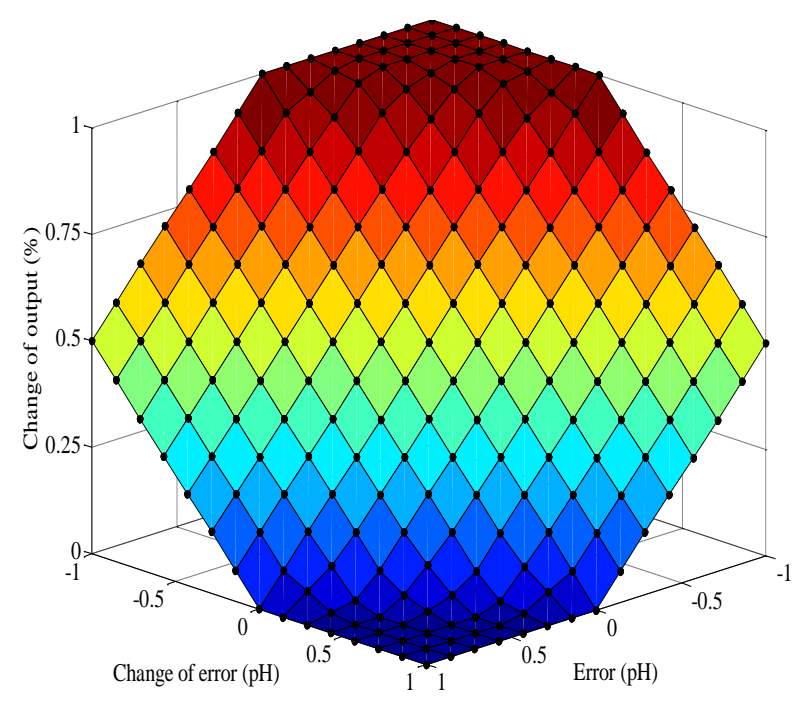

Figure 4. Normalized Fuzzy Controller Structure 
Table 1. Fuzzy Rule Base

\begin{tabular}{|c|c|c|c|c|c|c|c|}
\hline \multirow{2}{*}{$\mathrm{e}$} & \multicolumn{7}{|c|}{ ce } \\
\cline { 2 - 8 } & NL & NM & NS & ZE & PS & PM & PL \\
\hline NL & PL & PL & PL & PL & PM & PS & ZE \\
\hline NM & PL & PL & PL & PM & PS & ZE & NS \\
\hline NS & PL & PL & PM & PS & ZE & NS & NM \\
\hline ZE & PL & PM & PS & ZE & NS & NM & NL \\
\hline PS & PM & PS & ZE & NS & NM & NL & NL \\
\hline PM & PS & ZE & NS & NM & NL & NL & NL \\
\hline PL & ZE & NS & NM & NL & NL & NL & NL \\
\hline
\end{tabular}

The variables $\mathrm{k}_{1}, \mathrm{k}_{2}$, and $\mathrm{k}_{3}$ are positive scaling factors. The rule base for the input and output variables are shown in Table 1 . For $\mathrm{k}_{1}=\mathrm{k}_{2}=\mathrm{k}_{3}=1$, the normalized nonlinear output surface of the fuzzy controller is shown in Figure 4.

\section{FIS Optimization Using GA}

The flowchart for unconstrained and continuous GA optimization of FIS is shown in Figure 5. To optimize the FIS, the scaling factors $\mathrm{k}_{1}, \mathrm{k}_{2}$, and $\mathrm{k}_{3}$ are chosen so that they proportionately scale the vertices of membership functions for variables e, ce, and co respectively. The range of e, ce, and co are $\left[-\mathrm{k}_{1} \mathrm{k}_{1}\right],\left[-\mathrm{k}_{2} \mathrm{k}_{2}\right]$, and $\left[0 \mathrm{k}_{3}\right]$ respectively. GA optimization starts with an initial population of individuals of type 'double' and size 20, created randomly within the initial population range $\left[\mathrm{k}_{1 \min } \mathrm{k}_{2 \min } \mathrm{k}_{3 \min } ; \mathrm{k}_{1 \max } \mathrm{k}_{2 \max } \mathrm{k}_{3 \max }\right.$ ] where the subscripts 'min' and 'max' are representing minimum and maximum values respectively. We have $\mathrm{k}_{1 \min }=\mathrm{k}_{2 \min }=\mathrm{k}_{3 \min }=0, \mathrm{k}_{1 \max }=\mathrm{k}_{2 \max }=4.5$, and $\mathrm{k}_{3 \max } \in[260]$. Each individual in the population represents a potential solution to the optimization problem under consideration. The individuals evolve through successive iterations, called generations. During each generation, each individual in the population is evaluated using the fitness function. The evaluated fitness values of the individuals are ranked in an increasing order such that the best individual having minimum fitness value has the rank as 1 , the next best individual has the rank as 2 , and so on. The individuals with ranking 1 and 2 qualify for next generation population as elite children. The rank fitness scaling function is used to assign expectation values to the individuals which is inversely proportional to square root of their rank. Based on the assigned expectation values by the fitness scaling function, normalized expectation values for each individual in the population is calculated which is used by the selection function to select parents for next generation reproduction mechanism namely crossover and mutation. The stochastic uniform selection function is represented by a roulette wheel in which each individual corresponds to a section of the wheel equal to the normalized expectation value. A pointer then steps through the wheel in equal size steps, so as to cover the entire wheel in steps equals the required number of parents which is 32. At each step, the selection function creates a parent from the slot the pointer landed in. The GA uses selected parents to create next generation 14 crossover and 4 mutation children. The GA creates crossover children by combining a pair of parents whereas the mutation children are created by applying random changes to a single parent. The GA uses scattered crossover to create crossover children whereas the mutation children are created using Gaussian mutation. The procedure continues until the termination condition is satisfied. The GA uses maximum number of generations 100 , stall generations 50 , and fitness function tolerance $10^{-6}$ as the stopping criteria. Unless otherwise indicated, the values and procedure are true for both servo and regulatory operations of FLC. 


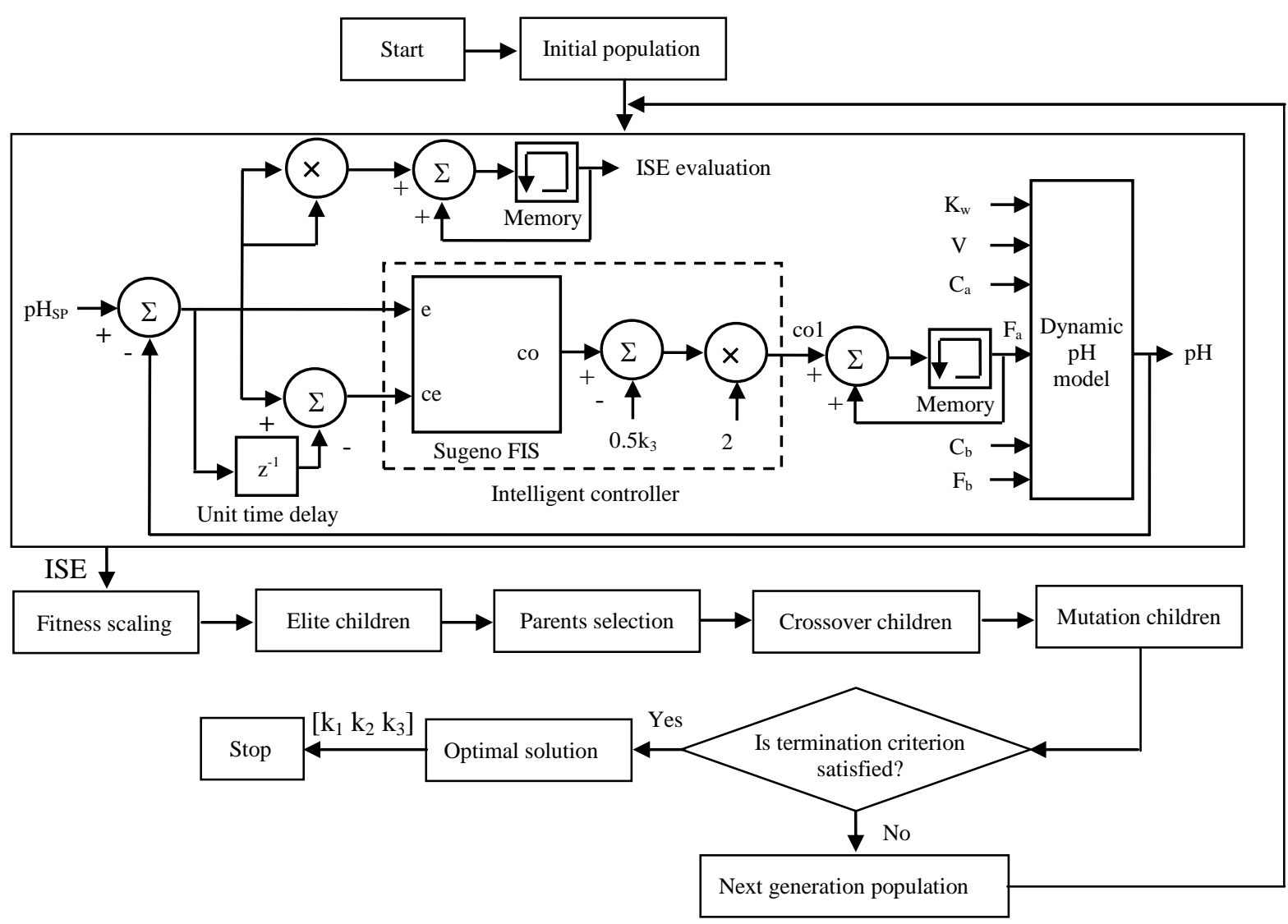

Figure 5. Unconstrained and Continuous GA Optimization Flowchart for Fuzzy Logic based pH Control

\section{Simulation Results and Discussions}

The performances of optimized conventional as well as adaptive controllers are compared for servo and regulatory control operations based on ISE, maximum overshoot and undershoot, and settling and rejection time (for $\pm 0.1 \mathrm{pH}$ error band) using MATLAB simulation. To calculate ISE, all the errors with magnitude greater than or equal to 0.01 are considered since further smaller errors will have negligible contribution.

\subsection{Servo Control}

For servo control, the optimal conventional FLC scheme is designed based on fixed $\mathrm{pH}_{\mathrm{SP}}$ variations of Case IA and tested for random $\mathrm{pH}_{\mathrm{SP}}$ variations of Case IB, while $\mathrm{F}_{\mathrm{b}}$ is kept constant at $1.75 \mathrm{~mL} / \mathrm{s}$. In Case IA, the $\mathrm{pH}_{\mathrm{SP}}$ is subjected to unit step changes in sequence of $7,8,9,10,9,8$, and 7 , and in Case $\mathrm{IB}$, the $\mathrm{pH}_{\mathrm{SP}}$ is subjected to random step variations in sequence of 7, 7.2, 7.6, 8.2, 9, 9.8, 9.7, 9.4, 8.9, 8.2, and 7.3, after every 4000 samples. The plot of best and mean values of ISE as a result of GA optimization for Case IA of conventional FLC is shown in Figure 6. The resulting best and mean ISE are 152.93 and 172.70 square $\mathrm{pH}$ respectively. The final mean fitness values are closer to best fitness values which indicate good GA convergence. The resulting optimal values of scaling factors are $\mathrm{k}_{1}=4.4568, \mathrm{k}_{2}=2.0409$, and $\mathrm{k}_{3}=0.9108$. The variations of controlled and manipulated variables for Case IA of conventional FLC for selected sample duration are shown in Figures 8 and 9 respectively. For Case IA of optimal conventional FLC, the largest settling time of 500 samples occurs when $\mathrm{pH}_{\mathrm{SP}}=9$ and $\Delta \mathrm{pH}_{\mathrm{SP}}=1$, and the largest undershoot of $3.86 \mathrm{pH}$ occurs when $\mathrm{pH}_{\mathrm{SP}}=10$ and $\Delta \mathrm{pH}_{\mathrm{SP}}=-1$. Using optimized conventional FLC designed for Case IA, the controller performance is tested for Case IB. 
The variations of controlled and manipulated variables for Case IB of conventional FLC for selected sample duration are shown in Figures 10 and 11 respectively. The resulting ISE is 37.49 square $\mathrm{pH}$. For Case IB of conventional FLC, the largest settling time of 393 samples occurs when $\mathrm{pH}_{\mathrm{SP}}=9$ and $\Delta \mathrm{pH}_{\mathrm{SP}}=0.8$, and the largest undershoot of $1.21 \mathrm{pH}$ occurs when $\mathrm{pH}_{\mathrm{SP}}=8.9$ and $\Delta \mathrm{pH}_{\mathrm{SP}}=-0.7$.

For servo control, to design optimal adaptive FLC scheme, GA optimization is performed individually at $\mathrm{pH}_{\mathrm{SP}}=7,7.25,7.5,7.75,8,8.25,8.5,8.75,9,9.25,9.5,9.75$, 10 with $\mathrm{F}_{\mathrm{b}}=1.75 \mathrm{~mL} / \mathrm{s}$ and change in set-point $\Delta \mathrm{pH}_{\mathrm{SP}}=0, \pm 0.25, \pm 0.5, \pm 0.75, \pm 1$ separately for $1 \leq \mathrm{k} \leq 4000$ samples at each $\mathrm{pH}_{\mathrm{SP}}$. The plot for optimal ISE, $\mathrm{k}_{1}, \mathrm{k}_{2}$, and $\mathrm{k}_{3}$ are shown in Figures 16, 17, 18, and 19 respectively. The variations of controlled and manipulated variables for Case IA of optimal adaptive FLC for selected duration are shown in Figures 24 and 25 respectively. For Case IA of optimal adaptive FLC, the ISE is 8.24 , the settling time is 2 samples when $\mathrm{pH}_{\mathrm{SP}}=9$ and $\Delta \mathrm{pH}_{\mathrm{SP}}=1$, and the undershoot is $0.08 \mathrm{pH}$ when $\mathrm{pH}_{\mathrm{SP}}=10$ and $\Delta \mathrm{pH}_{\mathrm{SP}}=-1$. For Case IB of optimal adaptive FLC, the scaling factors $\mathrm{k}_{1}, \mathrm{k}_{2}$, and $\mathrm{k}_{3}$ are chosen from the optimized adaptive set of readings of Case IA as shown in Table VI. The variations of controlled and manipulated variables for Case IB of optimal adaptive FLC for selected duration are shown in Figures 26 and 27 respectively. For Case IB of optimal adaptive FLC, the ISE is 4.64, the settling time is 2 samples when $\mathrm{pH}_{\mathrm{SP}}=9$ and $\Delta \mathrm{pH}_{\mathrm{SP}}=0.8$, and the undershoot is $0.08 \mathrm{pH}$ when $\mathrm{pH}_{\mathrm{SP}}=8.9$ and $\Delta \mathrm{pH}_{\mathrm{SP}}=-0.7$. The results are compared and summarized in Table II and Table III.

\subsection{Regulatory Control}

For regulatory control, the optimal conventional FLC scheme is designed based on fixed $F_{b}$ variations of Case IIA and tested for random $F_{b}$ variations of Case IIB, while $\mathrm{pH}_{\mathrm{SP}}$ is kept constant at 7. In Case IIA, the $\mathrm{F}_{\mathrm{b}}$ is subjected to step changes in sequence of $1.75,1.8375,1.75,1.925,1.75,2.0125,1.75,2.1$, and 1.75, and in Case IIB, the $\mathrm{F}_{\mathrm{b}}$ is subjected random step variations in sequence of $1.75,1.8025,1.75,1.89,1.75,1.9775$, $1.75,2.065$, and 1.75 , after every 4000 samples. The plot of best and mean values of ISE as a result of GA optimization for Case IIA of conventional FLC is shown in Figure 7. The resulting best and mean ISE are 457.55 and 515.70 square $\mathrm{pH}$ respectively. The final mean fitness values are closer to best fitness values which indicate good GA convergence. The resulting optimal values of scaling factors are $\mathrm{k}_{1}=2.8776, \mathrm{k}_{2}=4.2777$, and $\mathrm{k}_{3}=$ 1.3243. The variations of controlled and manipulated variables for Case IIA of conventional FLC for selected sample duration are shown in Figures 12 and 13 respectively. For Case IIA of optimal conventional $\mathrm{FLC}$, at $\mathrm{pH}_{\mathrm{SP}}=7$, the largest settling time of 43 samples and the largest undershoot of $2.42 \mathrm{pH}$ occurs when $\mathrm{F}_{\mathrm{b}}=2.1$ and $\Delta \mathrm{F}_{\mathrm{b}}=$ $-0.35 \mathrm{~mL} / \mathrm{s}$. Using optimized conventional FLC designed for Case IIA, the controller performance is tested for Case IIB. The variations of controlled and manipulated variables for Case IIB of conventional FLC for selected sample duration are shown in Figures 14 and 15 respectively. The resulting ISE is 511.48 square $\mathrm{pH}$. For Case IIB of conventional FLC, at $\mathrm{pH}_{\mathrm{SP}}=7$, the largest settling time of 49 samples and the largest undershoot of $2.35 \mathrm{pH}$ occurs when $\mathrm{F}_{\mathrm{b}}=2.065$ and $\Delta \mathrm{F}_{\mathrm{b}}=-0.315 \mathrm{~mL} / \mathrm{s}$.

For regulatory control, to design optimal adaptive FLC scheme, GA optimization is performed individually at $\mathrm{pH}_{\mathrm{SP}}=7,7.25,7.5,7.75,8,8.25,8.5,8.75,9,9.25,9.5,9.75$, 10 with $\mathrm{F}_{\mathrm{b}}=1.75 \mathrm{~mL} / \mathrm{s}$ and change in base flow $\Delta \mathrm{F}_{\mathrm{b}}=0, \pm 0.0875, \pm 0.175, \pm 0.2625$, and $\pm 0.35 \mathrm{~mL} / \mathrm{s}$ separately for $1 \leq \mathrm{k} \leq 4000$ samples at each $\mathrm{pH}_{\mathrm{SP}}$. The plot for optimal ISE, $\mathrm{k}_{1}, \mathrm{k}_{2}$, and $\mathrm{k}_{3}$ are shown in Figures 20, 21, 22, and 23 respectively. The variations of controlled and manipulated variables for Case IIA for selected duration are shown in Figures 28 and 29 respectively. For Case IIA of optimal adaptive FLC, at $\mathrm{pH}_{\mathrm{SP}}=7$, the ISE is 445.82 , the settling time is 37 samples and the undershoot is $2.44 \mathrm{pH}$ when $\mathrm{F}_{\mathrm{b}}=2.1$ and $\Delta \mathrm{F}_{\mathrm{b}}=-0.35 \mathrm{~mL} / \mathrm{s}$. For Case IIB of optimal adaptive FLC, the scaling factors $\mathrm{k}_{1}, \mathrm{k}_{2}$, and $k_{3}$ are chosen from the optimized adaptive set of readings of Case IIA as shown in 
Table VII. The variations of controlled and manipulated variables for Case IIB of optimal adaptive FLC for selected duration are shown in Figures 30 and 31 respectively. For Case IIB, at $\mathrm{pH}_{\mathrm{SP}}=7$, the ISE is 366.15 , the settling time is 35 samples and the undershoot is $2.36 \mathrm{pH}$ when $\mathrm{F}_{\mathrm{b}}=2.065$ and $\Delta \mathrm{F}_{\mathrm{b}}=-0.315 \mathrm{~mL} / \mathrm{s}$. The results are compared and summarized in Table IV and Table $\mathrm{V}$.

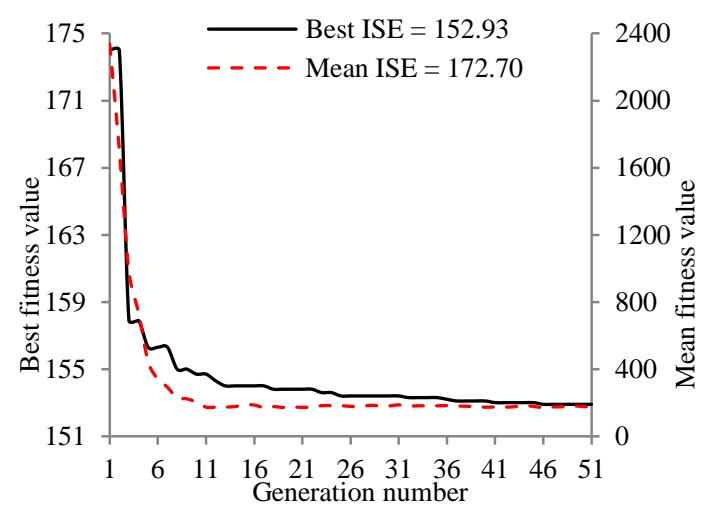

Figure 6. GA Optimization of Conventional FLC for Case IA

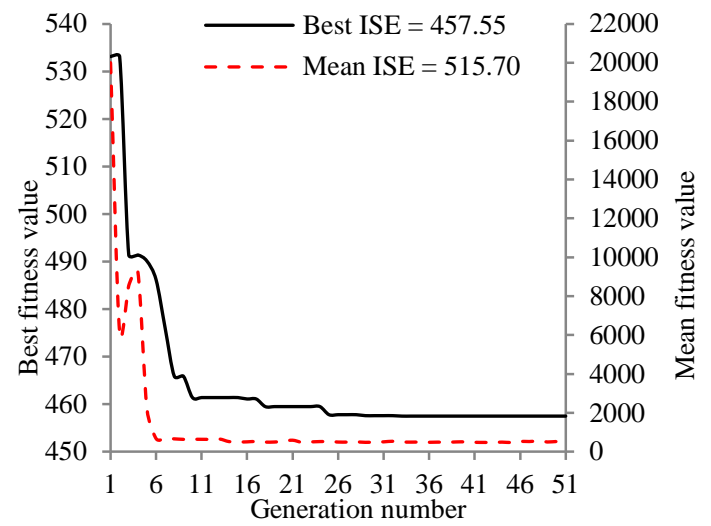

Figure 7. GA Optimization of Conventional for FLC for Case IIA

Table 2. Comparison of Servo FLC for Case IA

\begin{tabular}{|c|c|c|c|c|c|c|c|}
\hline \multicolumn{2}{|l|}{$\mathrm{pH}_{\mathrm{SP}}(\mathrm{pH})$} & 7 & 8 & 9 & 10 & 9 & 8 \\
\hline \multicolumn{2}{|l|}{$\Delta \mathrm{pH}_{\mathrm{SP}}(\mathrm{pH})$} & 1 & 1 & 1 & -1 & -1 & -1 \\
\hline \multirow{2}{*}{$\begin{array}{l}\text { Maximum } \\
\text { overshoot }^{*} \text { undershoot }\end{array}$} & Optimal conventional & 0.21 & 0.26 & 0.31 & 3.86 & 1.87 & 0.44 \\
\hline & Optimal adaptive & 0.00 & 0.00 & 0.00 & 0.08 & 0.07 & 0.46 \\
\hline \multirow{2}{*}{$\begin{array}{l}\text { Settling time (samples) } \\
( \pm 0.10 \mathrm{pH})\end{array}$} & Optimal conventional & 8 & 78 & 500 & 134 & 14 & 5 \\
\hline & Optimal adaptive & 1 & 1 & 2 & 3 & 3 & 5 \\
\hline \multirow{2}{*}{ ISE } & Optimal conventional & 1.22 & 4.04 & 26.20 & 109.0 & 11.0 & 1.33 \\
\hline & Optimal adaptive & 1 & 1 & 1.06 & 1.95 & 1.95 & 1.27 \\
\hline
\end{tabular}

${ }^{*}$ For positive $\Delta \mathrm{pH}_{\mathrm{SP}}$ and $\Delta \mathrm{F}_{\mathrm{b}} .{ }^{\#}$ For negative $\Delta \mathrm{pH}_{\mathrm{SP}}$ and $\Delta \mathrm{F}_{\mathrm{b}}$. 
Table 3. Comparison of Servo FLC for Case IB

\begin{tabular}{|l|l|l|l|l|l|l|l|l|l|l|l|}
\hline $\mathrm{pH}_{\mathrm{SP}}(\mathrm{pH})$ & 7 & 7.2 & 7.6 & 8.2 & 9 & 9.8 & 9.7 & 9.4 & 8.9 & 8.2 \\
\hline$\Delta \mathrm{pH}_{\mathrm{SP}}(\mathrm{pH})$ & 0.2 & 0.4 & 0.6 & 0.8 & 0.8 & -0.1 & -0.3 & -0.5 & -0.7 & -0.9 \\
\hline $\begin{array}{l}\text { Maximum } \\
\text { overshoot }^{*} / \mathrm{undershoot}^{\#} \\
(\mathrm{pH})\end{array}$ & $\begin{array}{l}\text { Optimal } \\
\text { conventional }\end{array}$ & 0.21 & 0.14 & 0.15 & 0.24 & 0.29 & 0.09 & 0.37 & 0.83 & 1.21 & 0.70 \\
\cline { 2 - 13 } & Optimal adaptive & 0.04 & 0.13 & 0.01 & 0.00 & 0.01 & 0.00 & 0.05 & 0.05 & 0.09 & 0.32 \\
\hline $\begin{array}{l}\text { Settling time (samples) } \\
( \pm 0.10 \mathrm{pH})\end{array}$ & $\begin{array}{l}\text { Optimal } \\
\text { conventional }\end{array}$ & 2 & 3 & 11 & 76 & 393 & 1 & 131 & 72 & 14 & 7 \\
\cline { 2 - 13 } & Optimal adaptive & 1 & 4 & 1 & 1 & 1 & 1 & 1 & 2 & 3 & 13 \\
\hline \multirow{2}{*}{ ISE } & $\begin{array}{l}\text { Optimal } \\
\text { conventional }\end{array}$ & 0.10 & 0.20 & 0.54 & 3.25 & 15.4 & 0.65 & 4.90 & 6.64 & 4.14 & 1.70 \\
\cline { 2 - 13 } & Optimal adaptive & 0.05 & 0.23 & 0.36 & 0.64 & 0.64 & 0.01 & 0.10 & 0.30 & 0.84 & 1.47 \\
\hline
\end{tabular}

Table 4. Comparison of Regulatory FLC for Case IIA

\begin{tabular}{|l|l|l|l|l|l|l|l|l|l|}
\hline \multicolumn{2}{|l|}{$\mathrm{F}_{\mathrm{b}}(\mathrm{mL} / \mathrm{s})$} & 1.75 & 1.8375 & 1.75 & 1.925 & 1.75 & 2.0125 & 1.75 & 2.1 \\
\hline \multicolumn{2}{|l|}{$\Delta \mathrm{F}_{\mathrm{b}}(\mathrm{mL} / \mathrm{s})$} & 0.0875 & $\begin{array}{l}- \\
0.0875\end{array}$ & 0.175 & -0.175 & 0.2625 & -0.2625 & 0.35 & -0.35 \\
\hline $\begin{array}{l}\text { Maximum } \\
\text { overshoot } \\
(\mathrm{pH})\end{array}$ & $\begin{array}{l}\text { Optimal } \\
\text { conventional }\end{array}$ & 1.46 & 1.46 & 1.92 & 1.92 & 2.21 & 2.21 & 2.42 & 2.42 \\
\cline { 2 - 11 } & $\begin{array}{l}\text { Optimal } \\
\text { adaptive }\end{array}$ & 1.48 & 1.44 & 1.92 & 1.92 & 2.23 & 2.23 & 2.44 & 2.44 \\
\hline $\begin{array}{l}\text { Settling time (samples }) \\
( \pm 0.10 \mathrm{pH})\end{array}$ & $\begin{array}{l}\text { Optimal } \\
\text { conventional }\end{array}$ & 11 & 11 & 22 & 22 & 32 & 31 & 42 & 43 \\
\cline { 2 - 10 } & $\begin{array}{l}\text { Optimal } \\
\text { adaptive }\end{array}$ & 9 & 10 & 17 & 18 & 26 & 26 & 44 & 37 \\
\hline \multirow{2}{*}{$\mathrm{ISE}$} & $\begin{array}{l}\text { Optimal } \\
\text { conventional }\end{array}$ & 10.92 & 10.92 & 32.08 & 32.08 & 66.49 & 66.51 & 120.5 & 118.0 \\
\cline { 2 - 10 } & $\begin{array}{l}\text { Optimal } \\
\text { adaptive }\end{array}$ & 8.99 & 8.26 & 30.67 & 30.70 & 67.51 & 67.53 & 115.7 & 116.5 \\
\hline
\end{tabular}

Table 5. Comparison of Regulatory FLC for Case IIB

\begin{tabular}{|c|c|c|c|c|c|c|c|c|c|}
\hline \multicolumn{2}{|l|}{$\mathrm{F}_{\mathrm{b}}(\mathrm{mL} / \mathrm{s})$} & 1.75 & 1.8025 & 1.75 & 1.89 & 1.75 & 1.9775 & 1.75 & 2.065 \\
\hline \multicolumn{2}{|l|}{$\Delta \mathrm{F}_{\mathrm{b}}(\mathrm{mL} / \mathrm{s})$} & 0.0525 & $\overline{-}-0.0525$ & 0.14 & -0.14 & 0.2275 & $\overline{-}-2275$ & 0.315 & -0.315 \\
\hline \multirow{2}{*}{$\begin{array}{l}\text { Maximum } \\
\text { overshoot }^{*} / \text { undershoot }^{\#} \\
(\mathrm{pH})\end{array}$} & $\begin{array}{l}\text { Optimal } \\
\text { conventional }\end{array}$ & 1.14 & 1.14 & 1.76 & 1.76 & 2.11 & 2.11 & 2.35 & 2.35 \\
\hline & $\begin{array}{l}\text { Optimal } \\
\text { adaptive }\end{array}$ & 1.15 & 1.14 & 1.77 & 1.77 & 2.13 & 2.13 & 2.36 & 2.36 \\
\hline \multirow{2}{*}{$\begin{array}{l}\text { Settling time (samples) } \\
( \pm 0.10 \mathrm{pH})\end{array}$} & $\begin{array}{l}\text { Optimal } \\
\text { conventional }\end{array}$ & 7 & 7 & 14 & 14 & 38 & 37 & 49 & 49 \\
\hline & $\begin{array}{l}\text { Optimal } \\
\text { adaptive }\end{array}$ & 12 & 10 & 18 & 20 & 25 & 25 & 34 & 35 \\
\hline \multirow{2}{*}{ ISE } & $\begin{array}{l}\text { Optimal } \\
\text { conventional }\end{array}$ & 4.45 & 4.45 & 20.35 & 20.36 & 79.70 & 82.57 & 149.8 & 149.8 \\
\hline & $\begin{array}{l}\text { Optimal } \\
\text { adaptive }\end{array}$ & 3.98 & 4.53 & 22.97 & 22.58 & 54.79 & 54.78 & 100.5 & 100.1 \\
\hline
\end{tabular}

Table 6. Adaptive Selection of Scaling Factors of FLC for Test Set Case IB Using Optimized Set of Case IA

\begin{tabular}{|l|l|l|l|l|l|l|l|l|l|l|l|}
\hline \multirow{2}{*}{ Test set } & $\mathrm{pH}_{\mathrm{SP}}(\mathrm{pH})$ & 7 & 7.2 & 7.6 & 8.2 & 9 & 9.8 & 9.7 & 9.4 & 8.9 & 8.2 \\
\cline { 2 - 12 } & $\mathrm{pH} \mathrm{HP}_{\mathrm{SP}}(\mathrm{pH})$ & 0.2 & 0.4 & 0.6 & 0.8 & 0.8 & -0.1 & -0.3 & -0.5 & -0.7 & -0.9 \\
\hline \multirow{2}{*}{ Optimized set } & $\mathrm{pH}_{\mathrm{SP}}(\mathrm{pH})$ & 7 & 7.25 & 7.75 & 8.25 & 9 & 9.75 & 9.75 & 9.25 & 8.75 & 8.25 \\
\cline { 2 - 11 } & $\mathrm{pH} \mathrm{H}_{\mathrm{SP}}(\mathrm{pH})$ & 0.25 & 0.5 & 0.5 & 0.75 & 1 & -0.25 & -0.5 & -0.5 & -0.75 & -1 \\
\hline
\end{tabular}

Table 7. Adaptive Selection of Scaling Factors of FLC for Test Set of Case IIB using Optimized Set of Case IIA

\begin{tabular}{|l|l|l|l|l|l|l|l|l|l|}
\hline \multirow{2}{*}{ Test set } & $\mathrm{F}_{\mathrm{b}}(\mathrm{mL} / \mathrm{s})$ & 1.75 & 1.8025 & 1.75 & 1.89 & 1.75 & 1.9775 & 1.75 & 2.065 \\
\cline { 2 - 10 } & $\Delta \mathrm{F}_{\mathrm{b}}(\mathrm{mL} / \mathrm{s})$ & 0.0525 & -0.0525 & 0.14 & -0.14 & 0.2275 & -0.2275 & 0.315 & -0.315 \\
\hline \multirow{2}{*}{ Optimized set } & $\mathrm{F}_{\mathrm{b}}(\mathrm{mL} / \mathrm{s})$ & 1.75 & 1.75 & 1.75 & 1.75 & 1.75 & 1.75 & 1.75 & 1.75 \\
\cline { 2 - 9 } & $\Delta \mathrm{F}_{\mathrm{b}}(\mathrm{mL} / \mathrm{s})$ & 0.0875 & -0.0875 & 0.175 & -0.175 & 0.2625 & -0.2625 & 0.35 & -0.35 \\
\hline
\end{tabular}

${ }^{*}$ For positive $\Delta \mathrm{pH}_{\mathrm{SP}}$ and $\Delta \mathrm{F}_{\mathrm{b}}$. ${ }^{\#}$ For negative $\Delta \mathrm{pH}_{\mathrm{SP}}$ and $\Delta \mathrm{F}_{\mathrm{b}}$. 


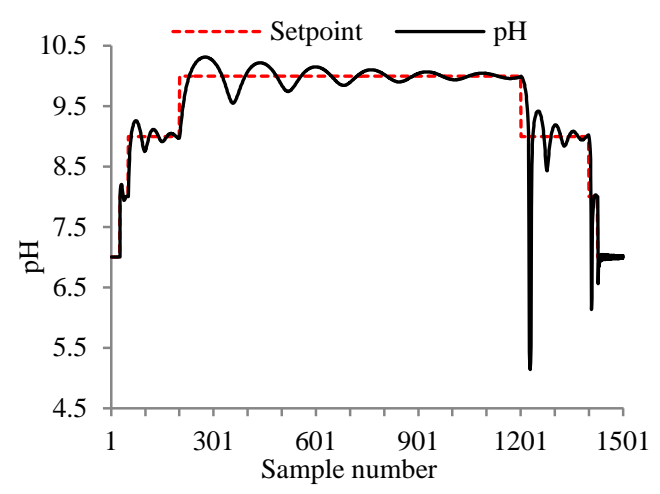

Figure 8. Controlled Variable Variations for Case IA

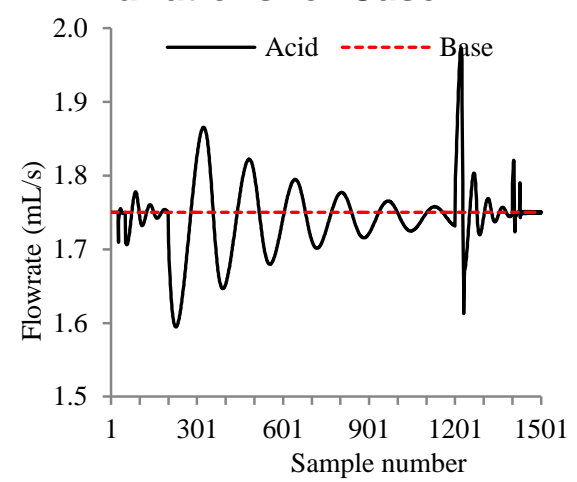

Figure 9. Manipulated Variable Variations for Case IA

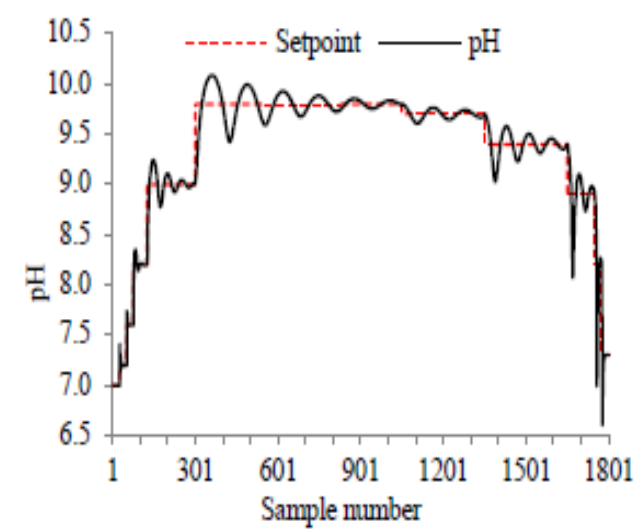

Figure 10. Controlled Variable Variations for Case IB

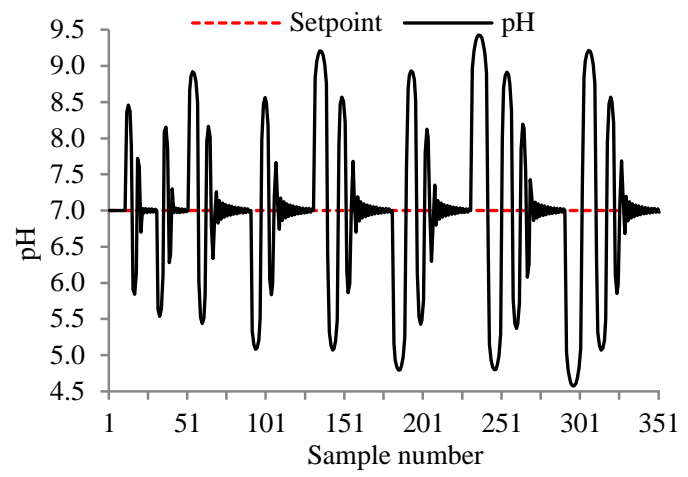

Figure 12. Controlled Variable Variations for Case IIA

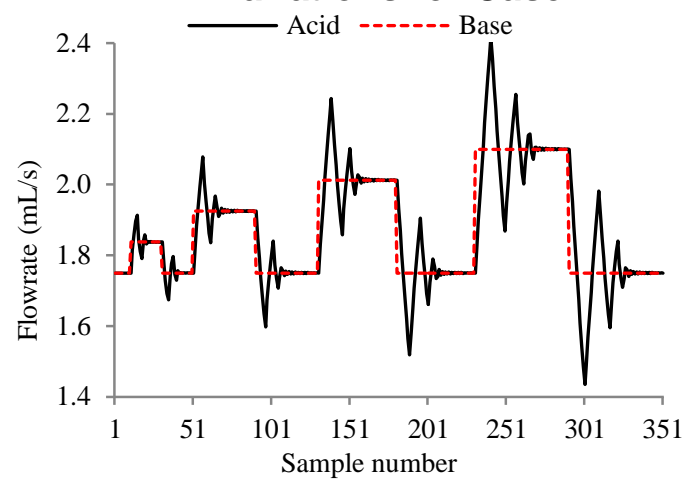

Figure 13. Manipulated Variable Variations for Case IIA

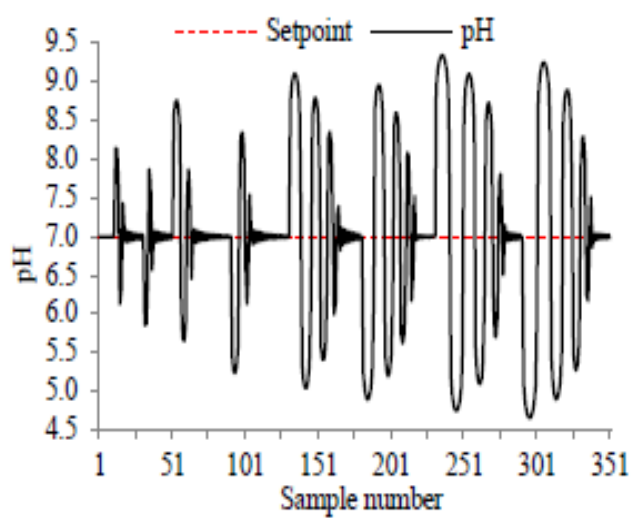

Figure 14. Controlled Variable Variations for Case IIB 


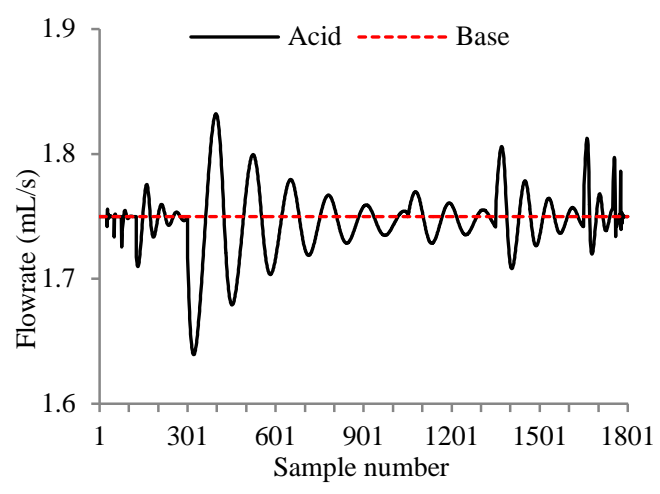

Figure 11. Manipulated variable for Case IB

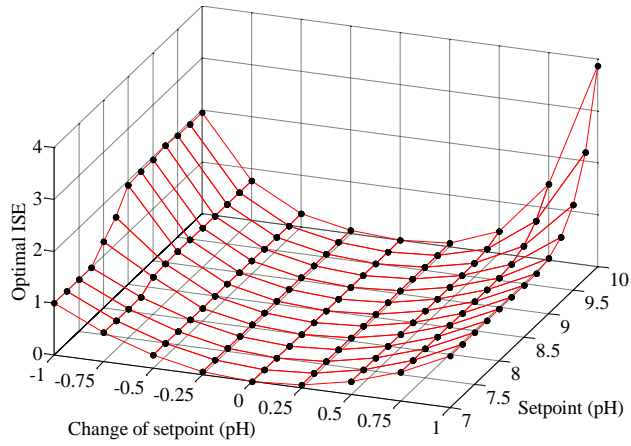

Figure 16. Optimal ISE for Adaptive Adaptive Servo Control

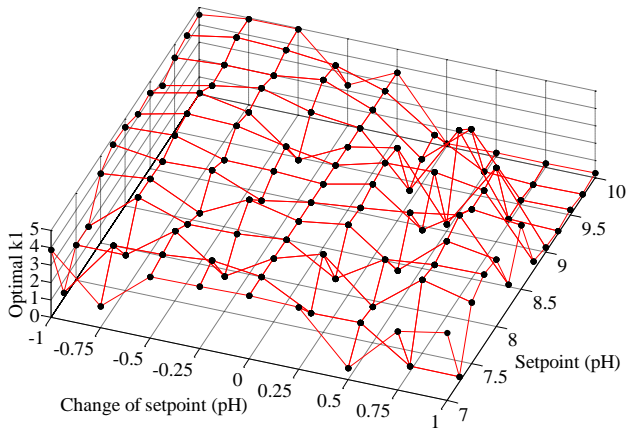

Figure 17. Optimal $k_{1}$ for Adaptive Servo Control

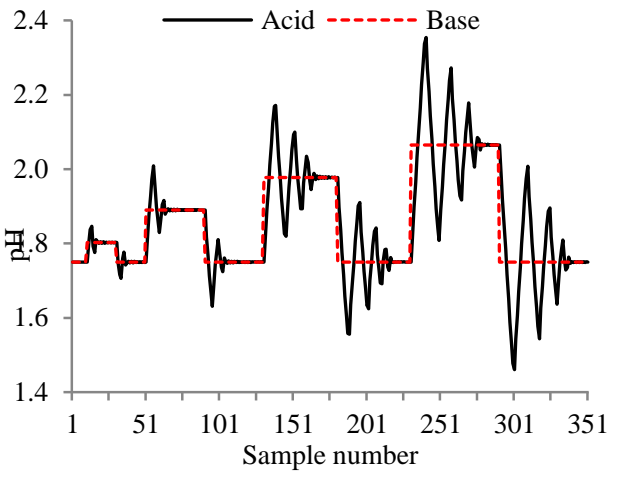

Figure 15. Manipulated Variations Variable Variations for Case IIB

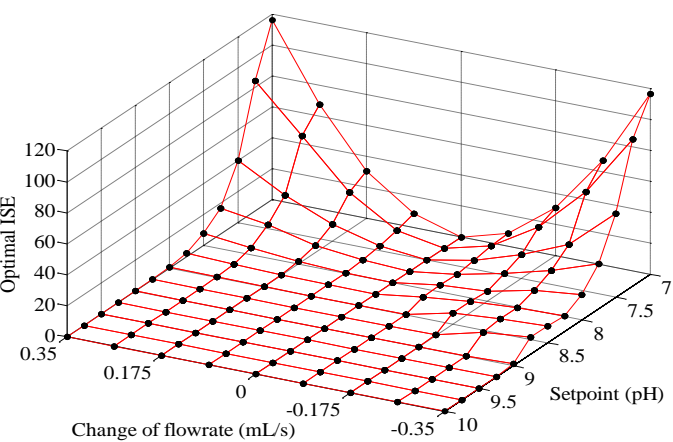

Figure 20. Optimal ISE for Regulatory Control

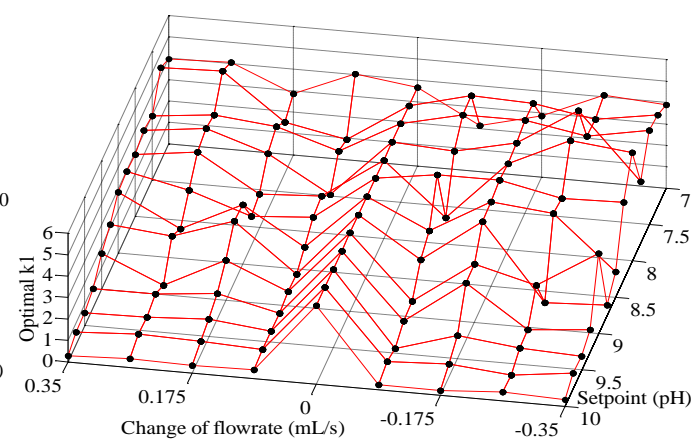

Figure 21. Optimal $k_{1}$ for Adaptive Regulatory Control

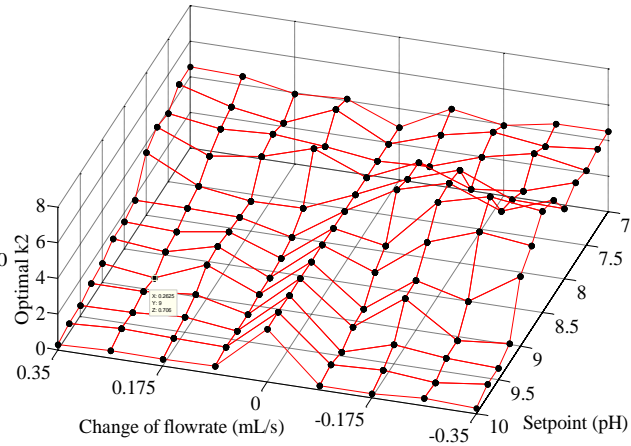

Figure 22. Optimal $k_{2}$ for Adaptive
Regulatory Control
Figure 22. Optimal $\mathbf{k}_{2}$ for Adaptive
Regulatory Control
Figure 18. Optimal $k_{2}$ for Adaptive Servo Control 


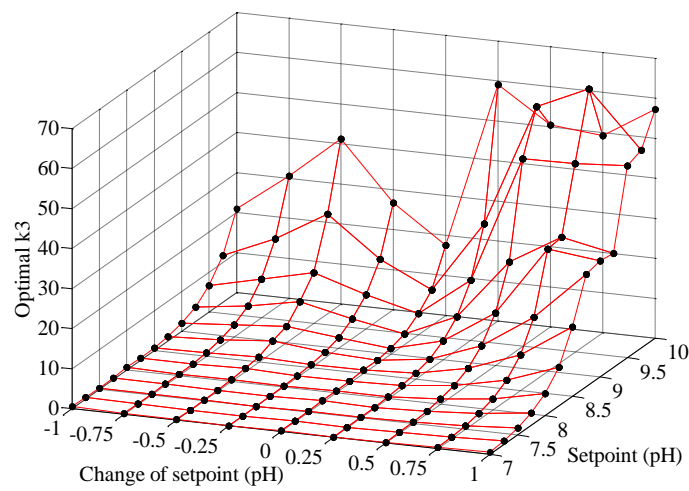

Figure 19. Optimal $k_{3}$ for Adaptive Servo Control

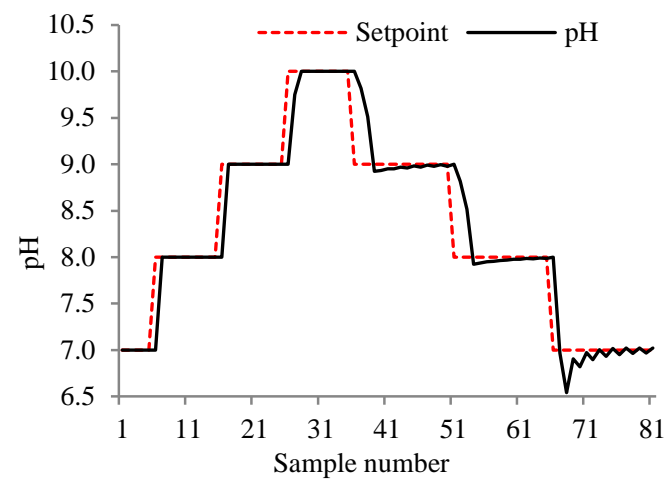

Figure 24. Controlled Variable Variations for Case IA

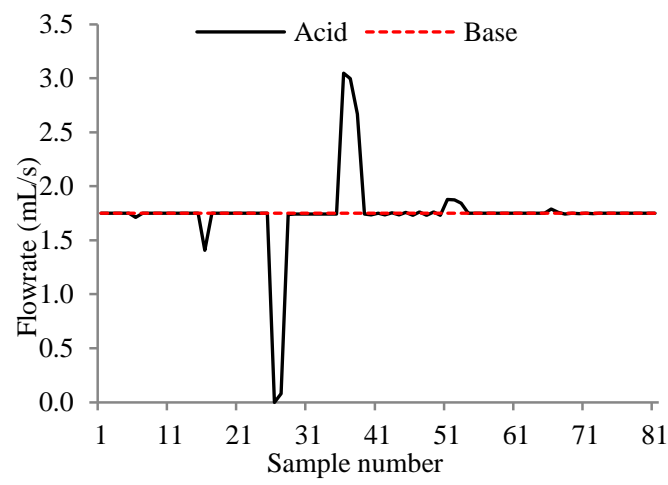

Figure 25. Manipulated Variable Variable Variations for Case IA

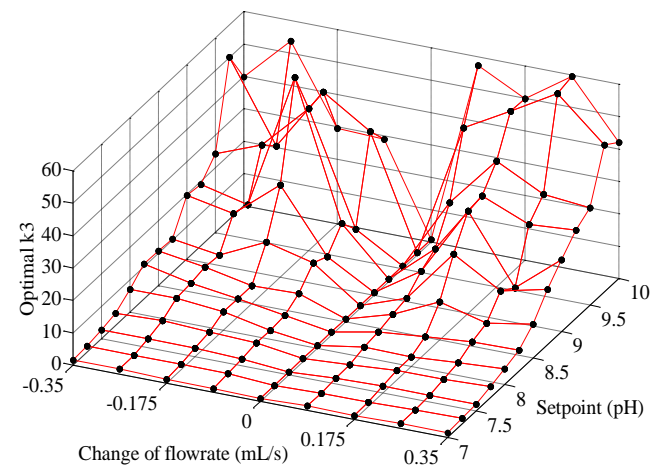

Figure 23. Optimal $\mathbf{k}_{3}$ for Adaptive Regulatory Control

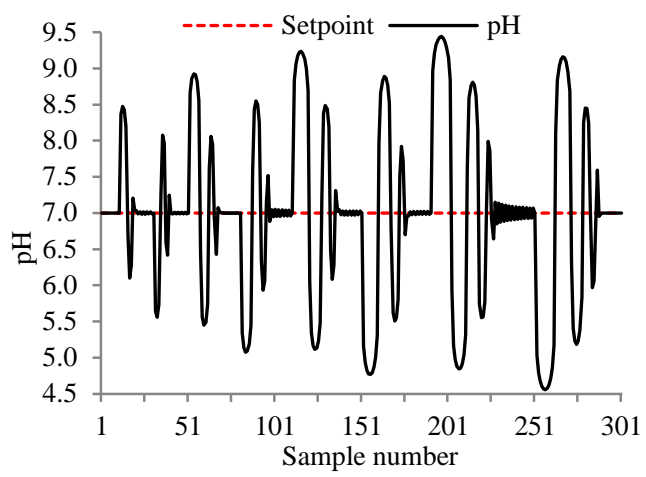

Figure 28. Controlled Variable Variations for Case IIA

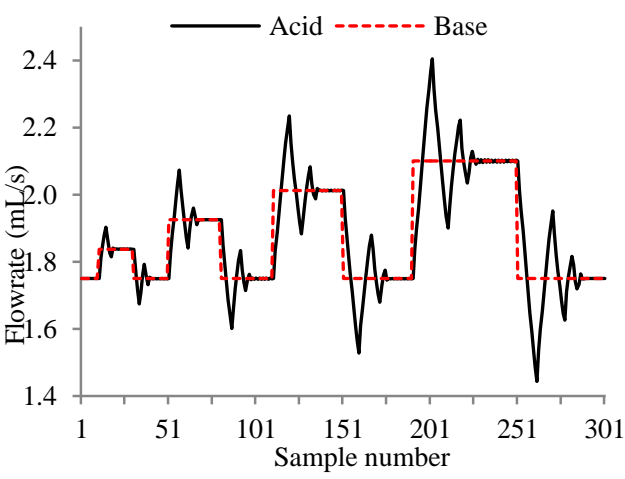

Figure 29. Manipulated Variations for Case

IIA 


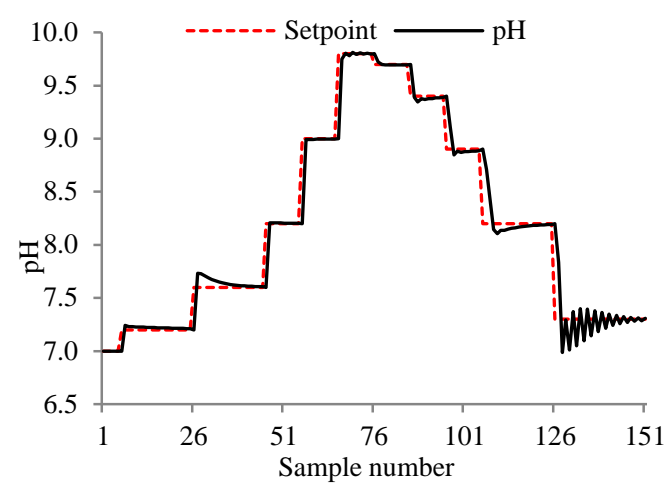

Figure 26. Controlled Variable Variations for Case IB

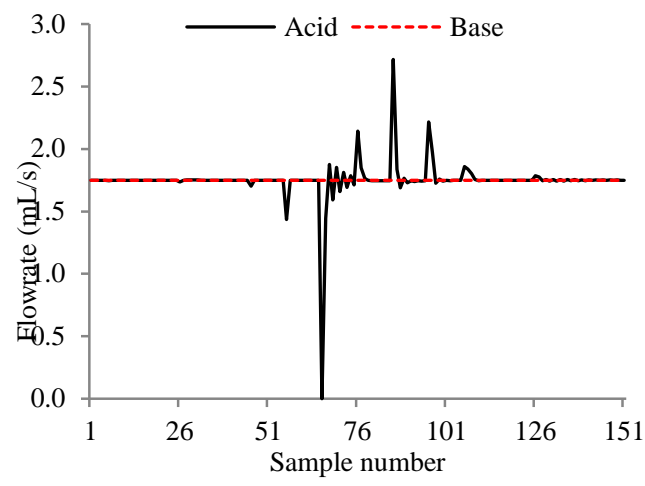

Figure 27. Manipulated Variable Variations for Case IB

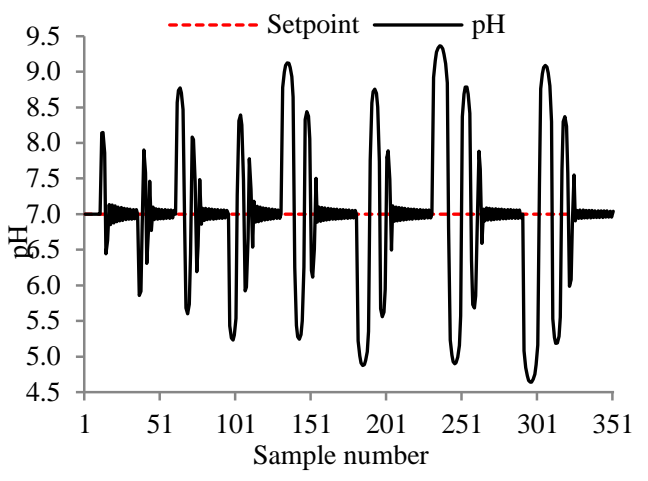

Figure 30. Controlled Variable Variations for Case IIB

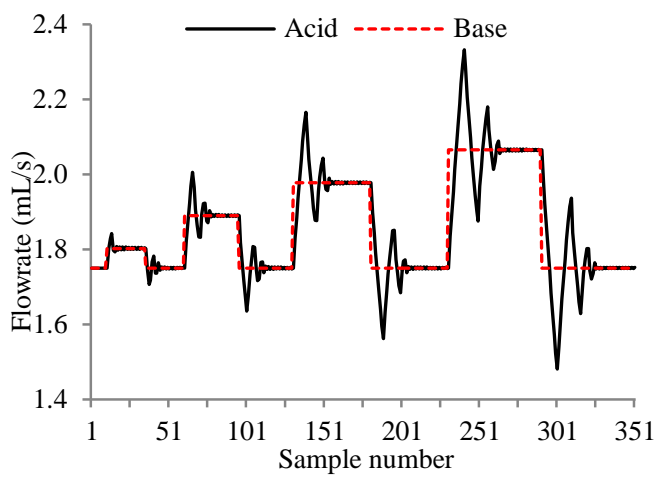

Figure 31. Manipulated Variable Variations for Case IIB

\section{Conclusion}

In this paper, an unconstrained, continuous and single-objective GA optimization based conventional FLC of $\mathrm{pH}$ neutralization process is developed for servo and regulatory control. To improve the controllers performance based on ISE, the adaptive FLC scheme is utilized to change the universe of discourse of input-output membership functions based on region of operation and amount of step change in set-point and load. For servo control design, the $\mathrm{pH}$ set-point is subjected to unit step changes in sequence as 7, 8, 9, $10,9,8$, and 7, at constant base flow of $1.75 \mathrm{~mL} / \mathrm{s}$. The GA optimized conventional FLC scheme resulted in ISE of 152.93 whereas the GA optimized adaptive FLC scheme resulted in ISE of 8.24 only. Both the controllers are tested for random variations in setpoint sequence of 7, 7.2, 7.6, 8.2, 9, 9.8, 9.7, 9.4, 8.9, 8.2, and 7.3 at constant base flow of $1.75 \mathrm{~mL} / \mathrm{s}$. For random set-point variations, the optimized conventional FLC scheme resulted in ISE of 37.49 whereas the optimized adaptive FLC scheme resulted in ISE of 4.64 only. Also significant improvement observed in settling time, overshoot, and undershoot in case of servo control, particularly for larger $\mathrm{pH}$ step change in set-point range of 8 to $10 \mathrm{pH}$. For regulatory control design, the base flow of $1.75 \mathrm{~mL} / \mathrm{s}$ is subjected to $\pm 0.0875, \pm 0.175, \pm 0.2625$, and $\pm 0.35 \mathrm{~mL} / \mathrm{s}$ step changes at constant $\mathrm{pH}$ of 7 . The optimized conventional FLC scheme resulted in ISE of 457.55 whereas the GA optimized adaptive FLC scheme resulted in ISE of 445.82. Both the controllers are tested for random variations in base flow sequence of 1.75, 1.8025, 1.75, 1.89, 1.75, 1.9775, 1.75, 2.065 , and $1.75 \mathrm{~mL} / \mathrm{s}$ at constant $\mathrm{pH}$ of 7 . For random base flow variations the optimized conventional FLC scheme resulted in ISE of 511.48 and the optimized adaptive FLC scheme resulted in ISE of 366.15. Also significant improvement observed in settling time 
in case of regulatory control, particularly for larger magnitude of base flow variations such as $\pm 0.3 \mathrm{~mL} / \mathrm{s}$.

\section{References}

[1] F. G. Shinskey, "Process-Control Systems: Application/Design/Adjustment", McGraw-Hill Publishers, USA, (1979).

[2] D. A. Mellichamp, D. R. Coughanowr and L. B. Koppel, "Characterization and gain identification of time varying flow processes", vol. 12, no. 1, (1966), pp. 75-82.

[3] D. A. Mellichamp, D. R. Coughanowr and L. B. Koppel, "Identification and adaptation in control loops with time varying gain", vol. 12, no. 1, (1966), pp. 83-89.

[4] T. J. McAvoy, E. Hsu and S. Lowenthal, "Dynamics of pH in controlled stirred tank reactor", vol. 11, no. 1, (1972), pp. 68-70.

[5] T. J. McAvoy, "Time optimal and Ziegler-Nichols control", vol. 11, no. 1, (1972), pp. 71-78.

[6] Y. -K. Yeo and T. -I. Kwon, "A neural PID controller for the pH neutralization process", vol. 38, no. 3, (1999), pp. 978-987.

[7] C. Venkateswarlu and R. Anuradha, "Dynamic fuzzy adaptive controller for pH", vol. 191, no. 12, (2004), pp. 1564-1588.

[8] W. W. Tan, F. Lu, A. P. Loh and K. C. Tan, "Modeling and control of a pilot pH plant using genetic algorithm", vol. 18, no. 4, (2005), pp. 485-494.

[9] T. K. Gustafsson and K. V. Waller, "Dynamic modeling and reaction invariant control of pH", vol. 38, no. 3, (1983), pp. 389-398.

[10] T. K. Gustafsson, "An experimental study of a class of algorithms for adaptive pH control", vol. 40, no. 5, (1985), pp. 827-837.

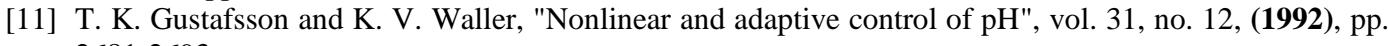
2681-2693.

[12] M. A. Henson and D. E. Seborg, "Adaptive nonlinear control of a pH neutralization process", vol. 2, no. 3, (1994), pp. 169-182.

[13] R. A. Wright and C. Kravaris, "Nonlinear control of pH processes using strong acid equivalent", vol. 30, no. 7, (1991), pp. 1561-1572.

[14] L. A. Zadeh, "Fuzzy sets", vol. 8, no. 3, (1965), pp. 338-353.

[15] L. A. Zadeh, "Outline of a new approach to the analysis of complex systems and decision processes", vol. SMC-3, no. 1, (1973), pp. 28-44.

[16] L. A. Zadeh, "Is there a need for fuzzy logic?", vol. 178, no. 13, (2008), pp. 2751-2779.

[17] E. H. Mamdani and S. Assilian, "An experiment in linguistic synthesis with a fuzzy logic controller", vol. 7, no. 1, (1975), pp. 1-13.

[18] P. J. King and E. H. Mamdani, "The application of fuzzy control systems to industrial processes", vol. 13, no. 3, (1977), pp. 235-242.

[19] E H. Mamdani, "Application of fuzzy logic to approximate reasoning using linguistic synthesis", vol. C26, no. 12, (1977), pp. 1182-1191.

[20] T. J. Procyk and E. H. Mamdani, "A linguistic self-organizing process controller", vol. 15, no. 1, (1979), pp. 15-30.

[21] T. Takagi and M. Sugeno, "Fuzzy identification of systems and its applications to modeling and control", vol. SMC-15, no. 1, (1985), pp. 116-132.

[22] R. Babuska, J. Oosterhoff, A. Oudshoorn and P. M. Bruijn, "Fuzzy self-tuning PI control of pH in fermentation", vol. 15, no. 1, (2002), pp. 3-15.

[23] S. Tzafestas and N. P. Papanikolopoulos, "Incremental fuzzy expert PID control", vol. 37, no. 5, (1990), pp. 365-371.

[24] C. -L. Chen and M. -H. Chang, "Optimal design of fuzzy sliding-mode control: A comparative study", vol. 93, no. 1, (1998), pp. 37-48.

[25] K. -H. Cho, Y. -K. Yeo, J. -S. Kim, \& Koh, S.-t. "Fuzzy model predictive control of nonlinear pH process", vol. 16, (1999), pp. 208-214.

[26] T. Bäck, "Evolutionary algorithms in theory and practice: Evolution strategies, evolutionary programming, genetic algorithms", Oxford University Press, UK, (1996).

[27] M. Mitchell, "An introduction to genetic algorithms", MIT press, (1998).

[28] J. H. Holland, "An introductory analysis with applications to biology, control, and artificial intelligence: Adaptation in natural and artificial systems", MIT press, USA, (1975).

[29] D. E. Goldberg, "Genetic algorithms in search, optimization, \& machine learning", Pearson, India, (2013).

[30] K. F. Man, K. S. Tang and S. Kwong, "Genetic algorithms: Concepts and applications", vol. 43, no. 5, (1996), pp. 519:534.

[31] J. J. Grefenstette, "Optimization of control parameters for genetic algorithms", vol. SMC-16, no. 1, (1986), pp. 122-128. 
[32] Y. -K. Yeo and T. -I. Kwon, "Control of pH processes based on the genetic algorithm", vol. 21, no. 1, (2004), pp. 3-15.

[33] C. L. Karr and E. J. Gentry, "Fuzzy control of pH using genetic algorithms", vol. 1, no. 1, (1993), pp. 46-53.

[34] S. -K. Oh, S. -B. Roh and H. -K. Kim, "Fuzzy controller design by means of genetic optimization and NFN based estimation technique", vol. 2, no. 3, (2004), pp. 362-373.

[35] S. -K. Oh and S.-B. Roh, "The design of fuzzy controller based on genetic optimization and neurofuzzy networks", vol. 5, no. 4, (2010), pp. 653-665.

\section{Authors}

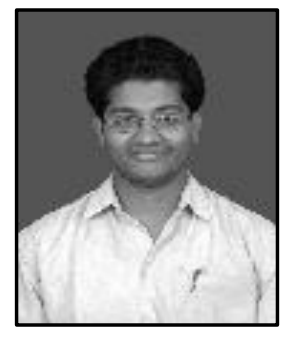

Parikshit Kishor Singh was born in Kolkata, India in 1977. He received the B.E. (Electronics Engineering) and M.Tech. (Electronics and Instrumentation) degrees from Sardar Vallabhbhai National Institute of Technology (SVNIT) Surat and National Institute of Technology (NIT) Warangal, in 2003 and 2005, respectively. In 2005, he joined the Vignan's Institute of Information Technology (VIIT) Vishakhapatnam as Assistant Professor, under Early Faculty Induction Programme (EFIP) of All India Council of Technical Education (AICTE). In 2007, he joined Birla Institute of Technology and Science (BITS) Pilani as Assistant Lecture. From 2009 onwards, he is designated as Lecturer at BITS Pilani. From 2008 onwards, he is pursuing his doctoral research in the area of applications of artificial intelligence in process control.

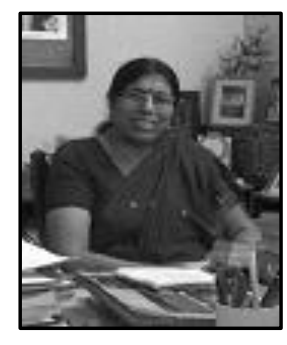

Surekha Bhanot was born in Patiala, India in 1957. She received the B.E. (Mechanical Engineering), M.Phil. (Instrumentation) and $\mathrm{Ph}$.D. degrees from Birla Institute of Technology and Science (BITS) Pilani, BITS Pilani and Indian Institute of Technology (IIT) Roorkee, in 1979, 1983 and 1995, respectively. In 1979, she joined BITS Pilani as Teaching Assistant. In 1983, she joined Thapar Institute of Engineering and Technology (TIET) Patiala. In 2002, she joined BITS Pilani as Associate Professor. From 2006 onwards, she is designated as Professor at BITS Pilani. Her research area of interest includes artificial intelligence applications in process modeling and control, biosensor design and applications, and biomedical signal processing and related instrumentation.

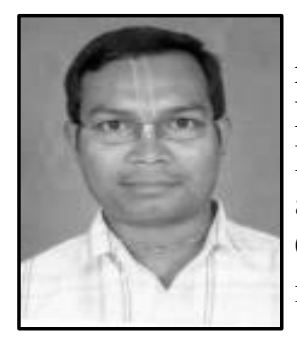

Hare Krishna Mohanta was born in Odisha, India in 1972. He received the B.E. (Chemical Engineering), M.Tech. (Chemical Engineering) and Ph.D. degrees from NIT Rourkela, IIT Kanpur and BITS Pilani, in 1995, 1998 and 2006, respectively. In 1995, he joined as a graduate engineer trainee in Indian Rare Earths Limited, Chhatrapur and worked for around one year before he left for MTech in IIT Kanpur. After completing MTech, he joined BITS Pilani as an Assistant Lecturer in 1998, became Lecturer in 2000 and Assistant Professor in 2006. He has over 16 years of teaching and 1 year industrial experience. His research area of interest includes advanced process control, process monitoring and control, applied wavelet analysis and modeling \& Simulation. 
International Journal of Control and Automation Vol. 7, No. 11 (2014) 